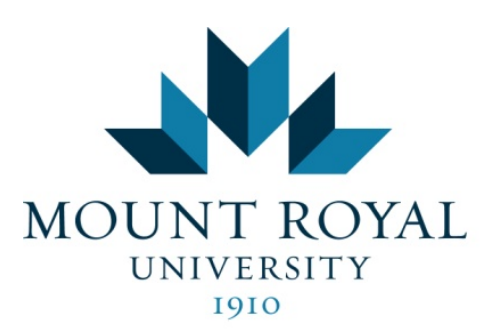

Mount Royal Undergraduate Education Review
Department of Education and Schooling

Volume 1(1)

Spring 2014

\title{
Is technology more important than friendships: A look into the effects of technology on communication skills and relationship building
}

Kayla Clampitt, Mount Royal University

\begin{abstract}
My research project is focused on how technology use can affect communication skills in children for their future. Conducting research through literature and surveys, I learned about both positive and negative uses of technology in classroom situations. I found that many people believe that the increased technology use our society is experiencing has a negative effect on children's' communicative future. However, there were also some findings that technology can have a positive impact on communication. These findings can help teachers and parents ensure their children are developing healthy communication skills.
\end{abstract}




\section{Introduction}

For my research project, I focused on finding out if technology use in the elementary classroom by elementary students hinders communication and relationship building skills. I wanted to find out in what areas technology may have positive effects on communication skills, and also in what areas technology may be negative on communication skills and relationships.

This area of study interested me because I think friendships are one of the most important aspects of a child's life. Nobody can go through life alone. Friends are the people you will make memories and experiences with, and they will also get you through the tough times of life. However, to make friends, children must have proper communication skills. Not only will these communication skills help start a new friendship by having the ability to break the ice and talk to somebody, but these skills will also help sustain the relationship, keeping it personal and interesting. If an individual does not know how to associate with another individual in a face-toface context, any relationships they may create will be very impersonal and meaningless.

I grew up in a very small rural town, meaning my entire education from kindergarten until I graduated from grade twelve was attended at a rural school. Being situated in literally the middle of nowhere, enrollment numbers at our schools were very low, meaning less funding was available. As a result, we lacked many of the resources that urban schools had the privilege of using on a daily basis, many of them being technologically based. This made the teaching style more traditional. In my opinion, I was very successful in this type of an education system, and so were most of my peers, scoring very good grades on our provincial and diploma exams. Due to my success with traditional learning, I became very closed off to the idea of using technology in the classroom. I thought it was only a distraction, and damaged the learning of students. However, as I have been observing different classroom practices and teaching styles in urban 
schools, I have realized there is a place for technology in the education system.

This discovery is what made me want to research the topic. I wanted to know how technology can be beneficial for communication development, and I also wanted to know how it can damage communication skills in youth. In my future teaching practice, I want to ensure I am implementing technology into my classroom, but I want it to be in the most successful ways. I want my students to be as successful as possible, while still being interested and engaged in the learning process. Not only do I want my students to do well in school, I want them to have the skills to create a healthy personal life for themselves, so they have a promising future in all areas, especially communication and relationships.

\section{Background}

As I began to research further into this topic, I realized it is a relatively new area of interest. Not a lot of research has been done on the connection between the use of technology and communication skills. I did manage to find a number of literature sources, consisting of journal and newspaper articles. The research included in the literature was mainly based on observations and personal opinions of the authors.

Although finding literature on this topic was challenging, I found a couple of sources that really helped me. Herman (2012) wrote an article explaining how increased technology use has impacted communication skills in youth. She investigated how important face-to-face communication is, and provided suggestions on how teachers and parents can help foster healthy communication development in their children while still letting them engage in technology use. Another article by Babic (2012) focused on children using technology in the classroom. She put her focal point on how important it is for students to have access to one-on-one technological devices. In the article "Effects of Technology on Communication," both the positive and 
negative aspects of using technology to develop communication skills were explored (Bethlehem, 2012). Both sides of the argument are summarized, and clear reasons are given to support the ideas. Lastly, Linder (2012) expresses her beliefs of technology use in the classroom, mostly focusing on the use of interactive whiteboards. She explores how technology use encourages students to collaborate with each other, and also how teachers can successfully use group work to help build communication between students.

I integrated these sources with the results from my survey as many of the suggestions and opinions given were similar between the two. The literature offered more of a professional viewpoint, and also gave specific figures and numbers for some statistics regarding technology use.

It is important to understand the background of this topic as I realized I would not be getting a direct answer on whether technology is beneficial or detrimental to a child's communication skills. The lack of prior research taught me early on that I would have to dig deep into the topic, view both sides of the argument, and base my conclusion on my personal opinion of the research results.

\section{Research Context and Methods of Investigation}

My study was conducted in my Mount Royal University Education 2325: Current and Emerging Technology Education class. To begin the research project, I completed the Government of Canada Human Research Ethics Certificate. This was so I understood how to properly conduct my research using other individuals, and to ensure the safety of my participants would always be kept as the number one concern.

To conduct my research, I first looked at published literature, as previously mentioned. I then created a Google Forms survey asking questions about daily technology use, daily 
communication, and what people's opinions were on the connection between the two. I sent this survey to my fellow university education students, my education professors, and the teachers at my past elementary and high schools. It was important for me to get some of these individuals to complete my survey as they have experience on a professional level working with students and observing them on a daily basis in a school setting. I also posted my survey on my Facebook page so I could get opinions from individuals who may just observe children in a public or private setting, not having the professional experience or training of working with them every day. The opinion of these individuals is also very important, as they may observe characteristics of children in natural environments that professionals may not get to see, or may overlook due to focusing on other aspects of the child. My survey clearly stated to every participant that their answers would remain private and anonymous.

To organize the data I received, I used Google Spreadsheets to put my survey question results into chart form so it was easier to analyze. Having a visual really helped me understand the opinions of my survey participants. I then sorted the written response questions from my survey into categories that I created, mainly focusing on separating them into positive aspects and negative aspects of technology on communication.

To analyze my literature research, I read through all the articles, writing down points that were relevant to my research. I then looked at these points and compared them to my survey results to examine the similarities and differences between the two sources of information.

\section{Findings}

The findings of my research presented many interesting facts about technology use and communication through both the literature and my survey results. Sixty-five individuals participated in my survey. Out of these participants, $72 \%$ of them were in the age range of 18- 
25, with $19 \%$ of the remaining participants belonging to the age group of 40 and above (Figure 1).

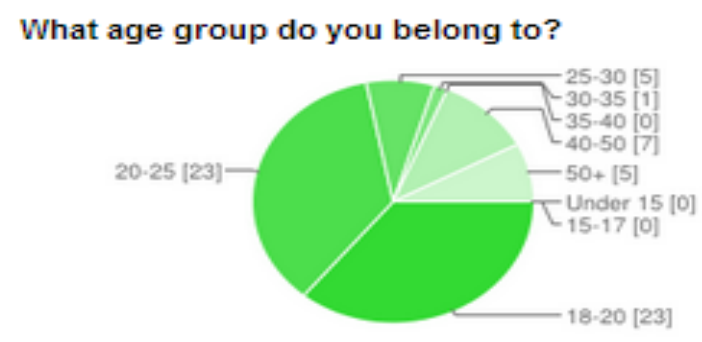

$\begin{array}{lrr}\text { Under } 15 & 0 & 0 \% \\ 15-17 & 0 & 0 \% \\ 18-20 & 23 & 38 \% 6 \\ 20-25 & 23 & 38 \% \\ 25-30 & 5 & 8 \% \\ 30-35 & 1 & 2 \% 6 \\ 35-40 & 0 & 0 \% 6 \\ 40-50 & 7 & 11 \% 6 \\ 50+ & 5 & 8 \%\end{array}$

Figure 1. The age groups of survey participants

A figure I found very alarming was that $40 \%$ of survey participants indicated that they spend over four hours a day using technology of some sort. Not falling far behind, $29 \%$ of the participants admitted to using technology for approximately 3-4 hours on a daily basis. None of the individuals that partook in my survey spend less than one hour a day on technology. Herman (2012) in a related research article stated that according to the Kaiser Foundation, children aged 8-18 are spending approximately 53 hours a week using some type of technology (p. 36). This averages out to participating in technology use for almost 8 hours every day! That's almost as long as most adults spend at work to earn a living to support their family! Thinking about these statistics and figures makes a person realize how much technology is impacting our lives, and makes us wonder if this impact has consequences (Figure 2).

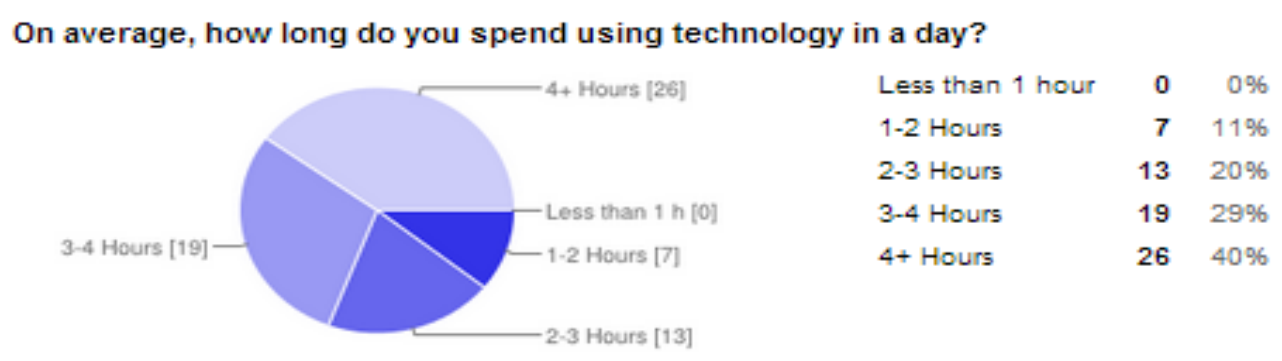

Figure 2. Average amount, in time, of technology use on a daily basis 
Another interesting piece of information I discovered from my survey results was where individuals are dominantly using technology. Fifty-two percent of the survey participants revealed that most of their technology use happens at home. This number was not surprising to me, as home is the place where individuals like to unwind, often watching a TV show or movie, or exploring the Internet to play games, read up on the interesting news of the day (including "news" from their Facebook or Twitter friends), or to participate in some online shopping. However, the number that did shock me was that $28 \%$ of my participants said that most of their technology use happens at school. I understand that the large majority of my participants were ages 18-25, which is the average age of university students. However, the fact that they use technology most often for educational purposes was a little astonishing. This revealed to me how important technology is becoming in the education system, and how important it is for teachers to understand the implications of technology use (Figure 3).

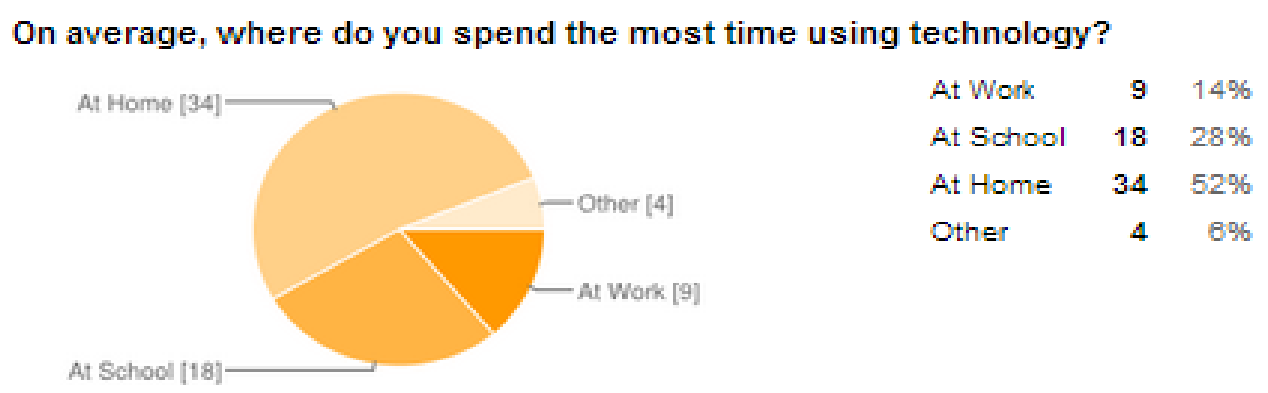

Figure 3. Where the majority of technology use is taking place

Along with discovering findings about technology use, I also discovered many things about communication. According to my results, $58 \%$ of individuals spend more than four hours a day communicating with others. Falling far behind, $18 \%$ said they spend 3-4 hours communicating with others on a daily basis. To build on this result, 55\% of participants revealed that greater than fifty percent of their communication is done in a face-to-face context. Only $5 \%$ 
of participants stated that only ten to thirty percent of their communication was done through face-to-face conversation, and 3\% stated that less than ten percent of their communication was done face-to-face. In my opinion, this number is quite interesting, as I expected a greater number of people to spend less than $50 \%$ of communication time actually talking to people in person, due to the large amount of time spent on technology (Figures 4 and 5).

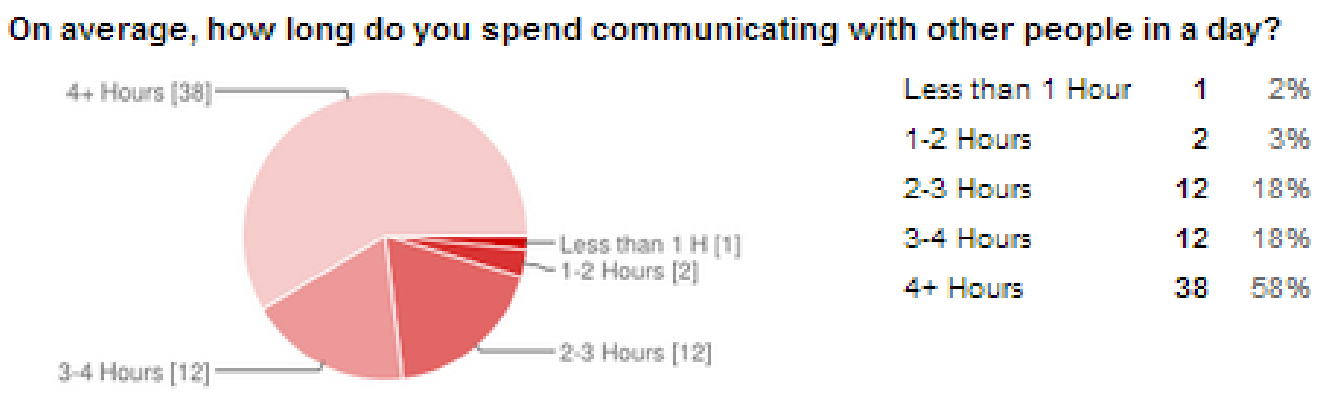

Figure 4. Average time spent communicating with others on a daily basis

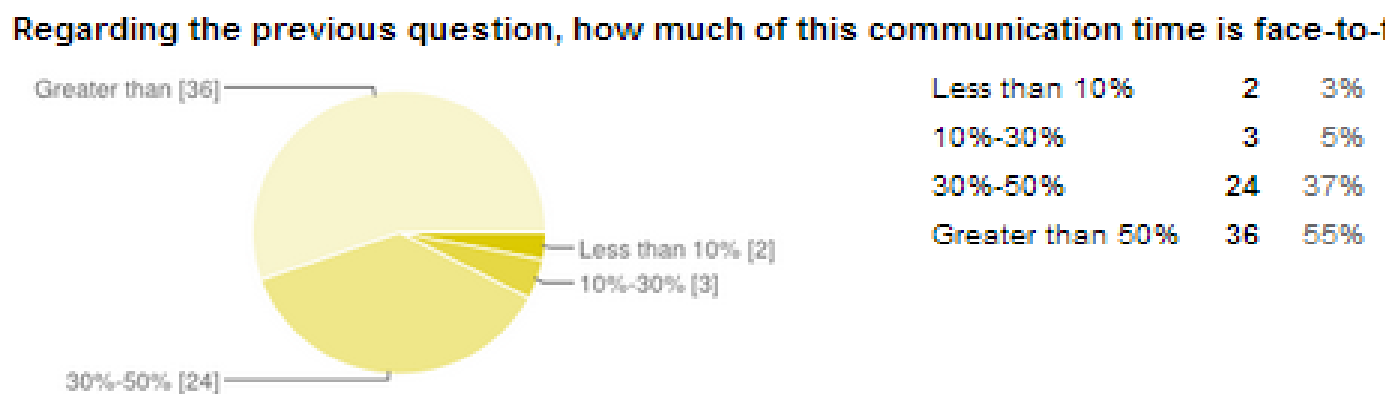

Figure 5. How much communication on a daily basis is face-to-face?

After examining the two main aspects of my study individually, I tried to make a correlation between technology and communication. When asked what types of technology individuals use to communicate with others, cell phones and social media came out on top by a large amount with 38\% and 32\% respectively. Surprisingly, the oldest type of technology on the list, the landline phone, was still used by 15\% of individuals (Figure 6). 


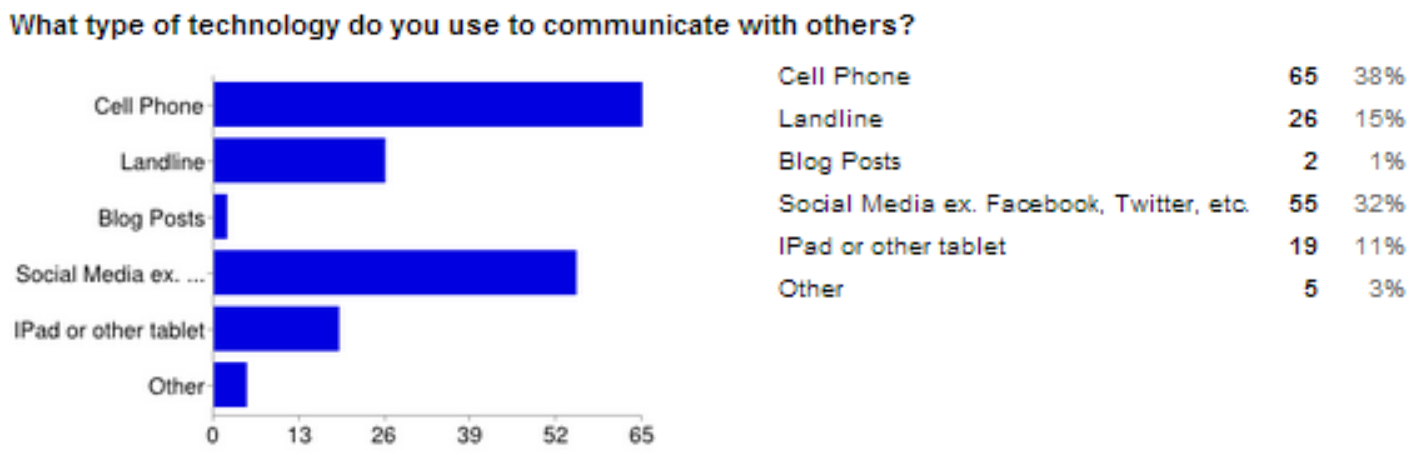

Figure 6. What type of technology people use to communicate with others

I then asked if people who had cell phones communicated more through text messaging or phone calls through their device. Out of the 65 participants, every single one owned a cell phone (Figure 7). Ninety-one percent of the participants indicated that they use text messaging more than actually making a phone call. While making a phone call is still using technology, the skills used in the converse are largely different than the skills needed for text messaging. In my own opinion, a conversation over a phone call is more similar to face-to-face communication than is text messaging as the pace of the conversation is still the same.

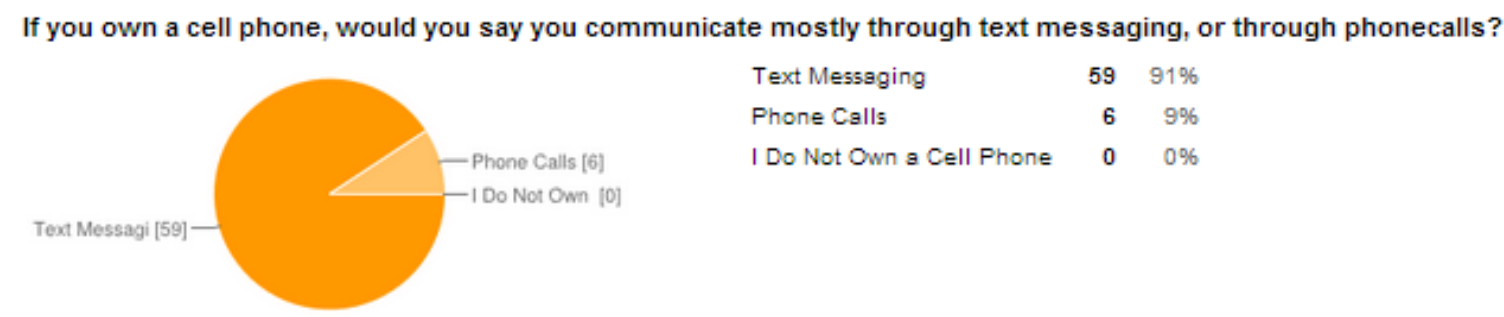

Figure 7. Is text messaging or phone calls used more often for communication?

Overall, 65\% of the survey participants believed that technology has caused them to participate less in face-to-face communication, and more in technological communication (Figure 8). This number is fairly significant, and can affect an individual's belief on whether or not technology is damaging communication skills, especially in youth. 


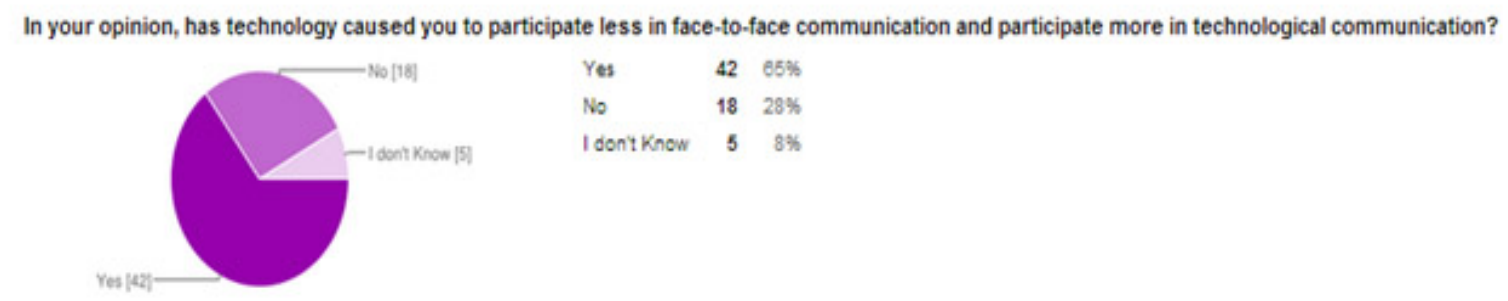

Figure 8. Impact of technology on face-to-face communication

Through the written response questions I included in my survey, and the literature I reviewed, I came to find that technology has both positive and negative effects on communication skills and relationships. The ideas and opinions my survey participants had aligned very closely with the findings I read about in the literature I reviewed.

One of the most dominant findings that came out of my survey results regarding positive aspects of technology was the ability to use it to communicate with people all over the world. Individuals believe technology "has a positive impact on communication skills because it allows people to stay connected with each other which leads to face to face contact” (Survey participant 27). If technological communication devices were not available, people would not have the ability to keep in contact with friends or family members that live far away, meaning relationships with these people would be impersonal, and maybe even non-existent. As Turcotte explained in Bethlehem's (2012) article, individuals have the opportunity to communicate with others 24/7 (Relationships, para. 1). Survey participant 14 believes “current technology...gives you a chance to communicate more often and with more people. The more you communicate the better your skills will become.”

This point leads to another positive feature of technology on communication that I discovered through my research. Technology encourages multiculturalism through the uses of Internet research and video calling tools (Bethlehem, 2012, Globalization, para. 1 \& 2). In turn, 
communication skills are enhanced as students are able to talk to other students from different countries and cultures over video conferencing. Developing these communication skills are very important as students learn how to interact with a variety of different people, and also learn how to communicate in difficult situations, as there may be a language barrier when conversing with other cultures.

The last major finding that portrayed technology as beneficial to communication was the speed and efficiency. Because "people have access to more people and outlets to communicate" (Survey participant 36), technology is very efficient in times of need. Faster communication with technology has the potential of big things, like saving lives (Bethlehem, 2012, Communication, para. 2). Being able to have instant communication with emergency crews can solve many problems our society faces.

As with all arguments, there are two sides to the story. Although there are many benefits of using technology for communication, there are also many negative results that technology can have on communication skills.

Many individuals believe that one of the greatest detriments of the increased use of technology in youth is the loss of empathy and ability to recognize and understand social cues (Herman, 2012, p. 37). Many believe that technology is "a lot less personal” and individuals "cannot always say things [in] the way a voice or facial expression can convey a message" (Survey participant 37). Because today's youth are constantly connected to each other through technology, many of them have lost the ability to engage in deep and meaningful conversations (Herman, 2012, p. 38). This is a direct relation to lacking knowledge of social cues. When children are unable to understand the body gestures or facial expressions being presented to them in conversation, they are too busy trying to analyze them that they are unable to fully listen and 
contribute to the rest of the conversation.

In relation to lacking knowledge of social cues, technology can cause much of our communication to be misinterpreted. Survey participant 12 stated that "since we lack tone and body language through most forms of communication, it is difficult to get the proper message across.” Technology cannot be used as a “substitute for communication” (Herman, 2012, p. 39). Face-to-face communication teaches many skills that cannot be taught through technological communication, including the ability to engage in appropriate responses to situations (Herman, 2012, p. 39). When children are unable to properly read into the small details of conversation, like body gestures, they can easily misinterpret what the speaker is intending to say. This can lead to many problems. The lack of social cues over text messaging also makes misinterpretation simple.

Another negative feature that technology has on communication skills is that children are becoming more anti-social as "there is just about $0 \%$ need for face to face communication anymore” (Survey participant 29). Today’s youth would rather sit at home and communicate constantly with each other through social media or text messaging than hang out with each other. When they do decide to actually hang out, it is realized that they "update each other so often that [they] talk about useless information to fill the void” (Survey participant 40). Therefore, even when they are hanging out in person, they are on their cell phones trying to avoid awkward situations.

\section{Conclusion and Recommendations}

One of the most important questions that I included in my survey was whether participants believed technology has a negative or a positive impact on communication skills. With an overwhelming result, 46 of my participants revealed that they believe technology has a 
negative influence on communication, while only 19 participants believed that technology has a positive influence on communication (Figure 9).

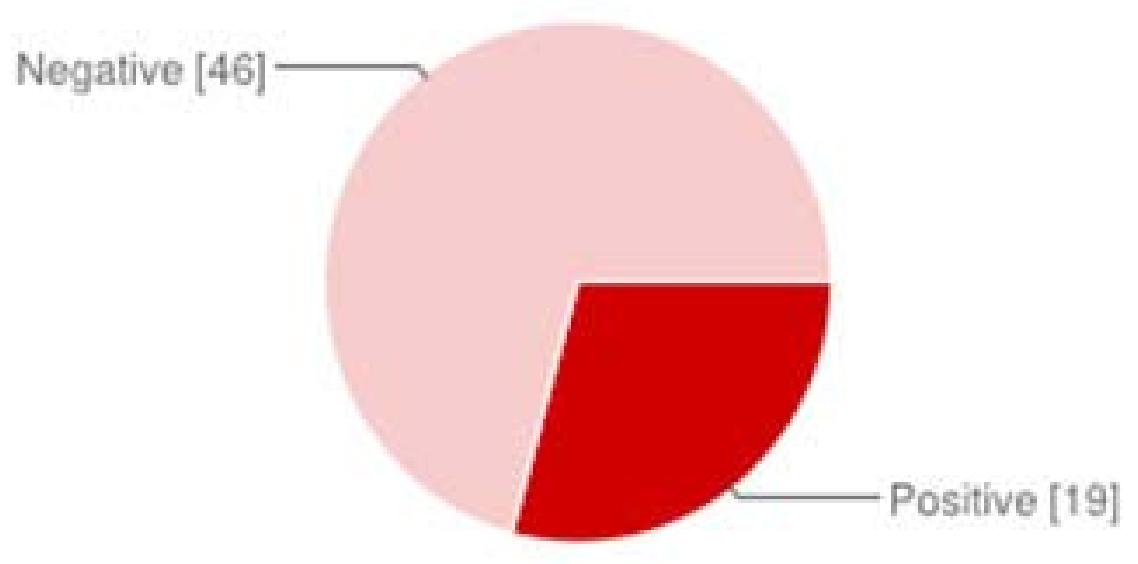

Figure 9. Does technology have a positive or negative impact on communication?

In the process of conducting my research study, I came across many great ideas through the literature, and my survey participants thought of many valid points and helpful suggestions for my future practices as a teacher.

As Survey participant 16 states, "A child who can confidently talk to other people -face to face- will do well through[out] their lives.” Parents and teachers need to understand how to encourage the best communication development in their children. To ensure that children are not spending too much time using technology, parents should restrict technology use to "no more than 2 hours” per night (Herman, 2012, p. 40).

There are also many implications for teachers in regards to technology use and communication. Using technology can help teachers encourage communication in the classroom through group work activities that encourage students to collaborate with each other and discuss the technology they are using, and how it is aiding their learning (Linder, 2012, p. 27). A large belief is that "in any classroom, especially an elementary one, the best way to enhance 
communication is thr[ough] participation” (Survey participant 14). If group work is being utilized in the classroom, even if technology is being used, children are still communicating with each other in a face-to-face context, and learning many valuable communication skills. I think another great idea is having specific times of day in the classroom where technology can be used, and restrict it from all other times of the day. Another alternative is to only use technology when it is absolutely necessary; "talk face-to-face with your friends in the classroom, and use technology for your friend who lives far away” (Survey participant 18). This is still encouraging the use of technology, increasing vital knowledge, but it is also encouraging personal communication.

In conclusion, it is very clear that there are both positive and negative aspects on communication when technology is used. Parents and teachers need to create a healthy balance between technological communication and face-to-face communication in order to ensure that all students are developing the knowledge that is fundamental to succeed in the future. It is important for adults to "teach kids to use technology as a life tool but that face to face communication is also very important in day to day life” (Survey participant 53). Understanding when technology is beneficial and when it is detrimental is a crucial skill that teachers need to learn and develop throughout their teaching experiences. As Survey participant 25 revealed, "not all technology is isolating, teachers just need to be choosy with which technology they choose and how often they allow their students to use it.”

In the future, more research needs to be completed to learn more about this topic. As it stands right now, there is no cemented answer on whether technology is beneficial or detrimental to communication skills in youth. More observations and experiments must be completed to discover more information on the topic so that teachers have a better idea of how to successfully 
implement communication technologies in their classrooms. In the meantime, teachers must trust their instincts and create a balance in the classroom to create well-rounded, successful students.

\section{Resources}

Babic, M. (2012). Pocket-Size REVOLUTION. Scholastic Administrator, 11(6), 41.

Bethlehem, P.A. (2012). Effects of technology on communication. US Fed News Service, Including US State News. HT Media Ltd.: Washington, D.C.

Herman, Y.M. (2012). Creating balance in the new age of technology. Montessori Life, 24(3), $36-43$

Linder, S. M. (2012). Interactive whiteboards in early childhood mathematics. Young Children,67(3), 26-35 